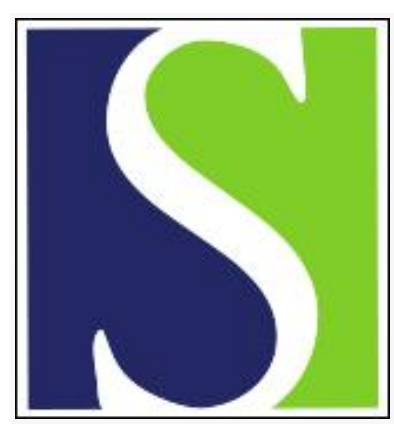

Scand J Work Environ Health 1976;2(1):37-41

https://doi.org/10.5271/sjweh.2834

Issue date: 1976

\title{
Carbon monoxide in foundry air.
}

by Virtamo M, Tossavainen A

Key terms: carbon monoxide; carboxyhemoglobin level; foundry air; foundry work

This article in PubMed: www.ncbi.nlm.nih.gov/pubmed/968463

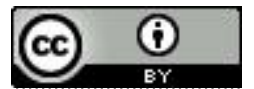




\title{
Carbon monoxide in foundry air
}

\author{
by MATTI VIRTAMO, M.Sc., ${ }^{1}$ and ANTTI TOSSAVAINEN, Lic.Sc. (Eng.) ${ }^{2}$
}

\begin{abstract}
VIRTAMO, M. and TOSSAVAINEN, A. Carbon monoxide in foundry air. Scand. $j$. work environ. \& health 2 (1976): suppl. 1, 37-41. The concentration of carbon monoxide in the air of 67 iron, steel, or copper alloy foundries using sand molding was measured. About 1,100 carbon monoxide determinations were made. High concentrations of carbon monoxide were found in the area around the cupolas and the casting sites in iron foundries. The blood carboxyhemoglobin levels of 145 workers from iron foundries were measured. The carboxyhemoglobin level of $6 \%$ was exceeded in $26 \%$ of the nonsmokers and in $71 \%$ of the smokers.
\end{abstract}

Key words: foundry work, carbon monoxide, carboxyhemoglobin level.

Carbon monoxide $(\mathrm{CO})$ in foundry air arises from the incomplete burning of carbonaceous material in the melting and casting processes $(2,3,4,5,7)$. The most important sources of carbon monoxide are the cupolas and the iron casting operation.

About 20 to $30 \%$ of the gases emitted from the cupolas is carbon monoxide, which can seep into the work environment if a leak occurs (4), exposing workers in the area to high concentrations of carbon monoxide.

Electric furnaces and oil-heated crucibles produce relatively little carbon monoxide, and harmful carbon monoxide concentrations do not develop during these melting processes.

During and after casting, the carbonaceous materials in the molding sand are burned by the hot metal, and carbon monoxide evolves. Carbon monoxide is produced from the coal, pitch, wood dust, starch, and other organic additives in the

1 Uusimaa Regional Institute of Occupational Health, Helsinki, Finland.

2 Department of Industrial Hygiene and Toxicology, Institute of Occupational Health, Helsinki, Finland.

Reprint requests to: Mr. Matti Virtamo, Uusimaa Regional Institute of Occupational Health, Arinatie 3, FIN-00370 Helsinki, Finland. molding sand and from the organic binders used for molds and cores. The molding sand used in iron foundries contains 3 to $10 \%$ coal powder and other additives, while fewer carbon monoxide producing materials are added to the sands used for steel and copper alloys $(5,7)$.

In addition to being formed during the melting and casting processes, carbon monoxide is emitted from the oil burners used for heating ladles and from the combustion engine loaders. In fettling shops welding and flame cutting produce minor amounts of carbon monoxide.

\section{MATERIAL AND METHODS}

If only the workers in the melting and casting areas are considered, about 1,300 men are exposed to carbon monoxide in Finnish foundries. There are about 900 such workers in iron foundries, about 200 in steel foundries, and about 200 in copper alloy foundries. The total number of foundrymen and foundries has been reported elsewhere (6).

We measured the carbon monoxide concentration in the air of 52 iron, 5 steel, and 10 copper alloy foundries. A total of about 1,100 air samples was taken. In 


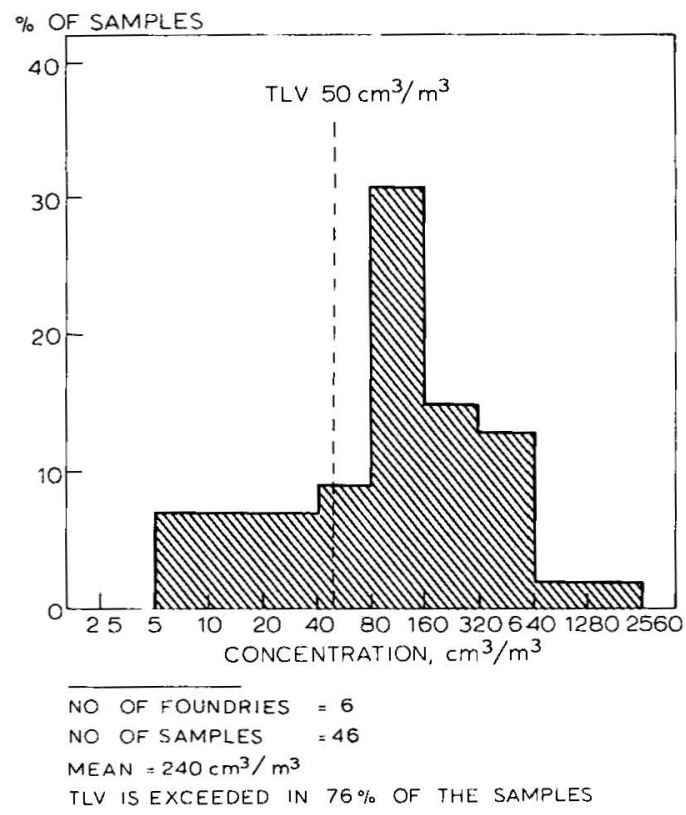

Fig. 1. Distribution of carbon monoxide concentrations around the cupolas.

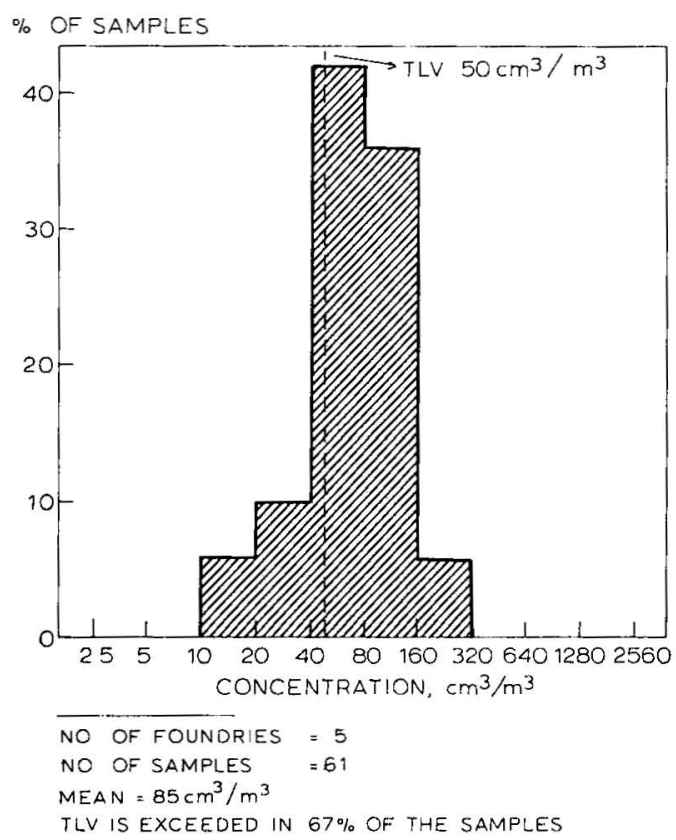

Fig. 3. Distribution of carbon monoxide concentration in the breathing zones of iron casters.

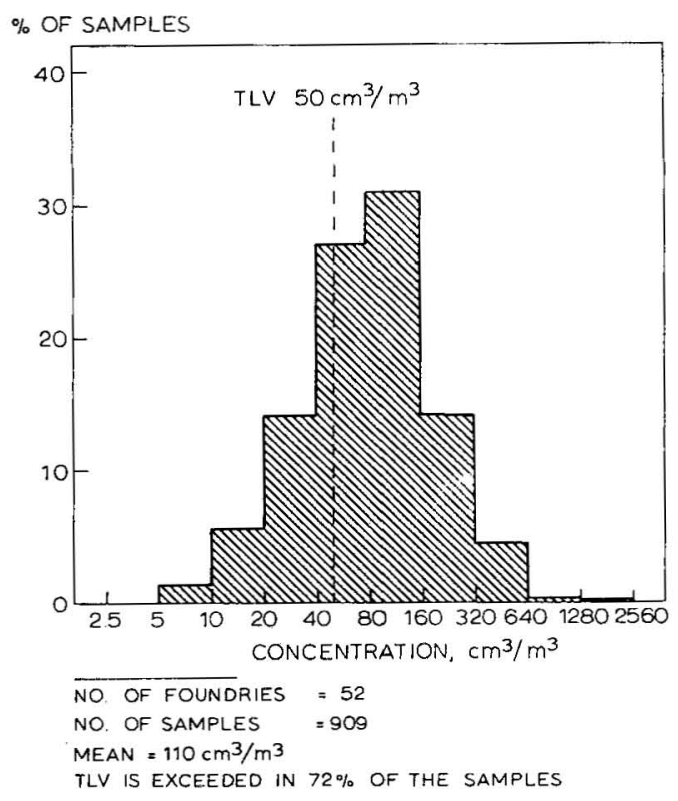

Fig. 2. Distribution of carbon monoxide concentrations in iron foundries during and after casting.

order to compare the foundry types and processes, we chose the sampling sites and the times of measurement uniformly for each foundry. The strategy was mainly planned so that information could be obtained about the origin and spread of carbon monoxide in the foundries.

For direct reading measurements a MSA portable $\mathrm{CO}$ indicator, model $\mathrm{D}$, and a gas detector, model $21 / 31$, by Drägerwerk AG were used. The MSA $\mathrm{CO}$ indicator has a measuring range of $0-500 \mathrm{~cm}^{3} / \mathrm{m}^{3}$, and it was calibrated with test gases with known carbon monoxide concentrations. With both types of equipment one measurement takes about $2 \mathrm{~min}$.

A worker's exposure was evaluated from samples taken from the breathing zone. The sampling tube was fixed to the shoulder of the worker, and the air was blown into a plastic bag with a portable MSA Monitaire Sampling Pump. The sampling time was $2 \mathrm{~h}$. The carbon monoxide concentrations were determined with a Wösthoff Ultragas conductivity analyzer (H. Wösthoff Apparatebau) (8). Samples were taken from the breathing 

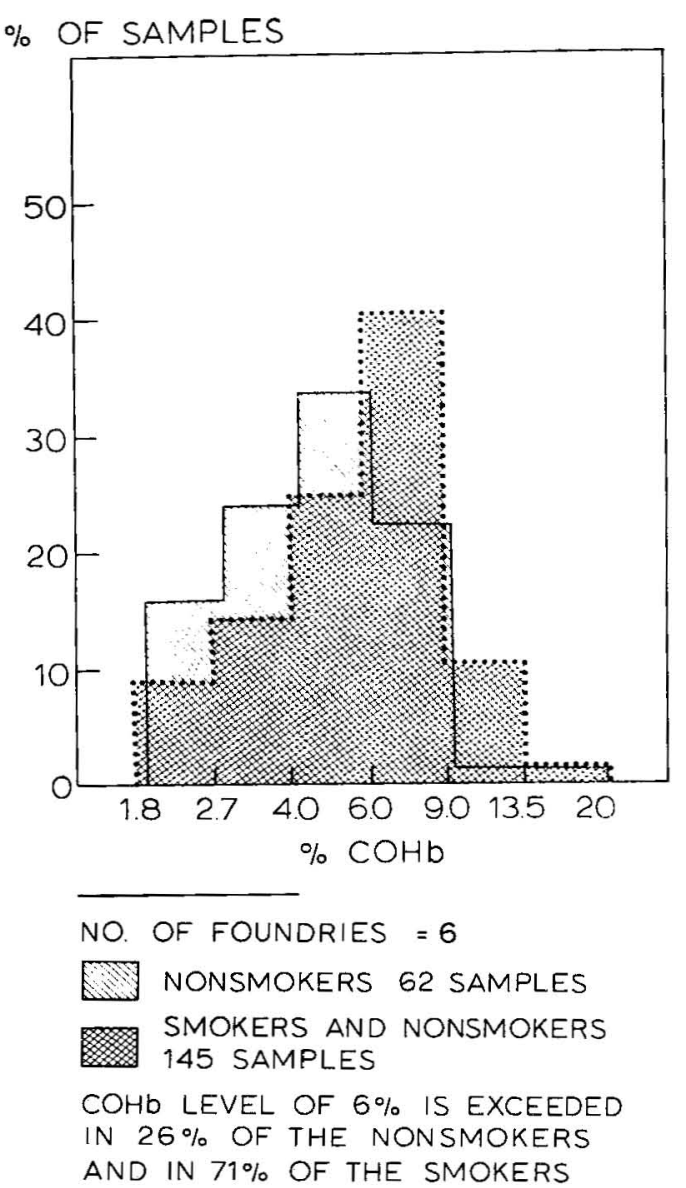

Fig. 4. Carboxyhemoglobin levels of carbon monoxide exposed iron foundry workers at the end of a work shift.

zone of 30 workers in five iron foundries, and the number of samples was 61 .

The blood carboxyhemoglobin levels of 145 workers from six iron foundries were measured. The subjects worked as cupola tenders, casters, and crane operators. The blood samples were taken immediately after the completion of a work shift. The subjects' smoking habits were recorded. We did not ask the subjects to refrain from smoking before the sampling procedure because we wanted the sample to be representative of their normal smoking routine. Carboxyhemoglobin values were determined with spectrophotometry (1).

\section{RESULTS}

\section{Iron foundries}

The arithmetic mean of the carbon monoxide concentrations was $240 \mathrm{~cm}^{3} / \mathrm{m}^{3}$ around the cupolas, $110 \mathrm{~cm}^{3} / \mathrm{m}^{3}$ in the casting area, and $85 \mathrm{~cm}^{3} / \mathrm{m}^{3}$ in the breathing zone of the casters. The threshold limit value (TLV) for carbon monoxide $\left(50 \mathrm{~cm}^{3} / \mathrm{m}^{3}\right)$ was exceeded in $76 \%$ of the cupola site measurements, in $72 \%$ of the casting area measurements, and in $67 \%$ of the samples from the breathing zones of casters (figs. 1-3).

The measured carboxyhemoglobin levels of the iron foundry workers are presented separately for the smokers and nonsmokers in fig. 4. The $6 \%$ carboxyhemoglobin level was exceeded in $26 \%$ of the nonsmokers and in $71 \%$ of the smokers.

\section{Steel foundries}

According to our spot-check sampling, the carbon monoxide concentrations were less than $20 \mathrm{~cm}^{3} / \mathrm{m}^{3}$ in the areas around the electric furnaces of the steel foundries. In the steel casting areas the mean carbon monoxide concentration was $18 \mathrm{~cm}^{3 /}$ $\mathrm{m}^{3}$, and $9 \%$ of the measurements exceeded the TLV (fig. 5).

\section{Copper alloy foundries}

In the melting and casting area of the copper alloy foundries the mean carbon monoxide concentration was $20 \mathrm{~cm}^{3} / \mathrm{m}^{3}$, and $20 \%$ of the measurements exceeded the TLV (fig. 6). High concentrations $\left(100-300 \quad \mathrm{~cm}^{3} / \mathrm{m}^{3}\right)$ appeared only momentarily around the oil-heated crucibles when they were lit.

\section{DISCUSSION}

The present study indicates that carbon monoxide concentrations exceeding the TLV do appear in foundry work, especially in iron foundries around the cupolas and in the casting areas. When evaluating the results, one must remember that a worker's exposure to carbon monoxide also depends on how long he stays in these areas. 


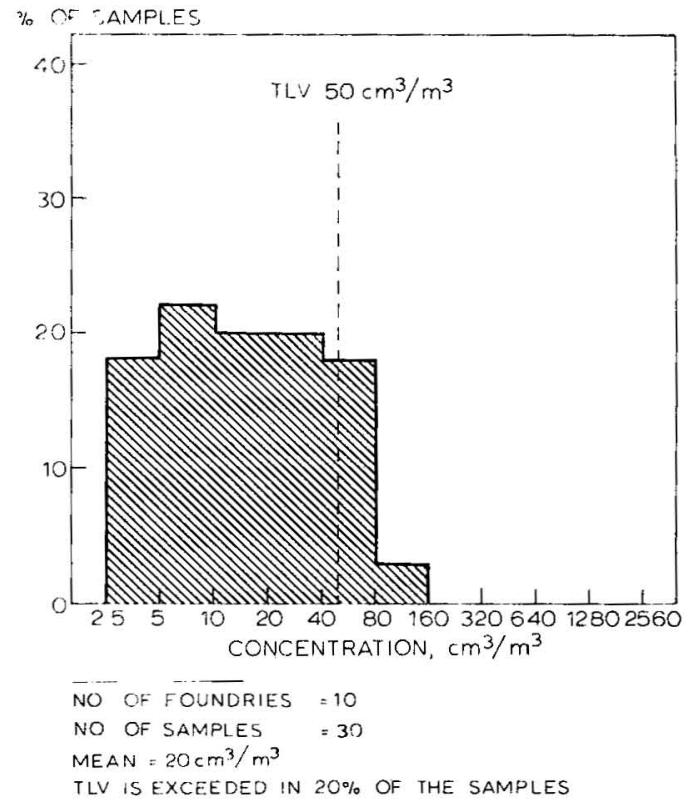

Fig. 5. Distribution of carbon monoxide concentrations in steel foundries during and after casting.

Workers in steel and copper alloy foundries are less exposed to carbon monoxide than those in iron foundries. The carboxyhemoglobin levels of the iron foundry workers were high and indicated occupational exposure to carbon monoxide. The carboxyhemoglobin levels of the smokers were clearly higher than those of the nonsmokers. In addition to the occupational carbon monoxide exposure there was an obvious added effect from smoking.

In order to prevent the health hazard created by the presence of carbon monoxide in the air, foundries should reduce the carbon monoxide concentrations in the air with technical means and provide for the regular monitoring of both the carbon monoxide concentrations in the air and the carboxyhemoglobin levels of the workers. Insulating the furnaces against leaks and installing efficient local and general exhaust systems lower the carbon monoxide levels in the air of work sites. In addition foundries can reduce carbon monoxide concentrations in the casting

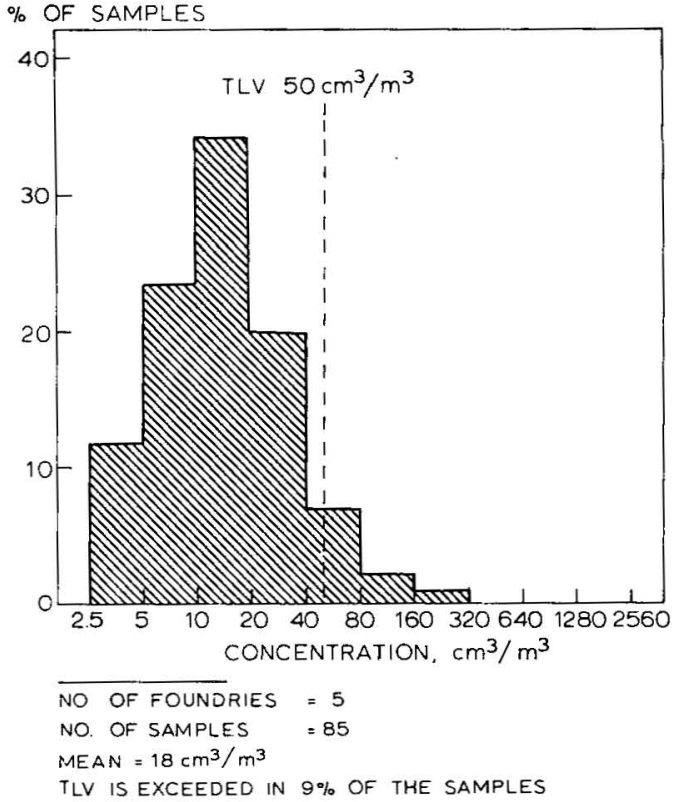

Fig. 6. Distribution of carbon monoxide concentrations in copper alloy foundries during and after casting.

areas by installing local exhaust systems, enclosing the conveyors, and by blowing clean air into the work sites.

A good ventilation system in the casting area is also important because other harmful gases, such as those formed from the pyrolysis of resin binders, can be present.

Properly choosing the quality and quantity of the molding sand additives may reduce the amount of carbon monoxide formed during casting.

\section{REFERENCES}

1. FRETWURST, F., MEINECKE, K. H. Eine neue Methode zur quantitativen Bestimmung des Kohlenoxydhämoglobins im Blut. Arch. toxicol. (Berl) 17 (1959) 273-283.

2. HOFIG, R. Probleme der Luftverunreinigung bei der Verwendung von Kunstharzbindern. Giessereitechnik 15 (1969) 250-254.

3. PATTY, F. A. Industrial hygiene and toxicology (vol. 2, 2nd revised ed.) Interscience Publishers, New York, N.Y. 1967, p. 2258. 
4. SCHMIDT, K. G. Staubbekämpfung in der Giesserei-Industrie, 2 Aufl. VDI-Verlag, Düsseldorf 1967, pp. 107, 110 \& 329.

5. SIEPMANN, H., PUUTZ, M. and SWEGAT, W. Die Gas- und Staubentwicklung beim Herstellen von Formen und Kernen nach dem Maskenformverfahren. Giesserei 56 (1969) 113-200.
6. TOSSAVAINEN, A. Metal fumes in foundries. Scand. $j$. work environ. \& health 2 (1976): suppl. 1, 42-49.

7. TUBICH, G. E. Health studies of the shell moulding process. Arch ind. health 21 (1960) 424.

8. VERDIN, A. Gas analysis instrumentation. MacMillan, London 1973, p. 191. 